\title{
PELATIHAN DIGITAL MARKETING BAGI ANGGOTA NASYIATUL AISYIYAH PURBALINGGA DALAM MENGHADAPI ERA PASAR GLOBAL DAN PENGEMBANGAN INDUSTRI KREATIF
}

\author{
Siti Alvi Sholikhatin ${ }^{1)}$, Wanda Fitrianingsih"), Sahira Dhiyaulhaq ${ }^{2)}$ \\ 1)Program Studi Informatika, Fakultas IImu Komputer, Universitas Amikom Purwokerto, Purwokerto, \\ Jawa Tengah, Indonesia \\ 2)Program Studi Bisnis Digital, Fakultas Bisnis dan IImu Sosial, Universitas Amikom Purwokerto, Purwokerto, \\ Jawa Tengah, Indonesia \\ Corresponding author : Siti Alvi Sholikhatin \\ E-mail : sitialvi@amikompurwokerto.ac.id
}

Diterima 09 Juli 2021, Direvisi 30 Juli 2021, Disetujui 30 Juli 2021

\begin{abstract}
ABSTRAK
Kemajuan teknologi adalah sebuah keniscayaan, konektivitas menjadi sebuah kebutuhan yang tidak bisa dipisahkan dari gaya hidup masyarakat. Aktivitas yang sebelumnya hanya bisa dilakukan dengan cara-cara konvensional, sekarang bisa dilakukan secara daring tanpa batasan ruang dan waktu. Salah satu dampak yang terpengaruh secara langsung oleh digitalisasi adalah transaksi dan perdagangan. Pemasaran konvensional pun kini telah bergeser ke pemasaran digital atau digital marketing. Digital marketing merupakan kegiatan bisnis baik penjualan maupun pemasaran yang memanfaatkan teknologi digital sebagai media. Pelatihan digital marketing terhadap anggota Nasyiatul 'Aisyiyah cabang Rabak Purbalingga dilakukan dengan metode webinar, yaitu memberikan informasi secara daring mengenai strategi digital marketing, dengan tujuan agar ilmu pemasaran secara digital dapat diimplementasikan secara maksimal oleh anggota Nasyiatul 'Aisyiyah. Di masa pandemi dimana kegiatan transaksi melalui internet semakin marak dilakukan, maka momentum ini dirasa tepat untuk belajar mengembangkan keahlian berbisnis dan mengamalkan ilmu digital marketing demi meningkatkan pendapatan keluarga dan memberdayakan perempuan di tengah masyarakat. Media digital marketing yang diajarkan pada webinar ini yaitu: Whatsapp, Facebook, dan Instagram, dimana ketiga media sosial tersebut merupakan salah satu yang paling banyak digunakan sekarang, sehingga jangkauan pangsa pasarnya cukup menjanjikan. Hasil pengabdian yaitu ibu-ibu mempraktikkan cara membuat story di Whatsapp agar menarik, serta diberi tips-tips dalam mengelola akun media sosial baik instagram maupun facebook agar menarik dan dapat dimaksimalkan untuk media promosi digital sehingga ikut berkontribusi dalam menghadapi era pasar global dan mampu turut serta dalam mengembangkan industri kreatif.
\end{abstract}

Kata kunci: digital marketing; nasyiatul 'aisyiyah; webinar; pengabdian masyarakat

\begin{abstract}
Technological advancement is inevitable, connectivity becomes a necessity that can not be separated from the lifestyle of society. Activities that previously could only be done in conventional ways, can now be done online without any restrictions on space and time. One of the impacts directly affected by digitization is transactions and trade. Conventional marketing has now shifted to digital marketing. Digital marketing is a business activity of both sales and marketing that utilizes digital technology as a medium. Digital marketing training for members of Nasyiatul 'Aisyiyah Rabak Purbalingga branch is conducted by webinar method, which is to provide information online about digital marketing strategy, with the aim that digital marketing knowledge can be implemented to the maximum by Nasyiatul 'Aisyiyah members. In a pandemic where internet transaction activities are increasingly being carried out, this momentum is felt appropriate to learn to develop business skills and practice digital marketing to increase family income and empower women in the community. Digital media marketing taught in this webinar is: Whatsapp, Facebook, and Instagram, where these three social media are one of the most used now, so the reach of market share is quite promising. The result of devotion is that the members practice how to create stories on Whatsapp to be interesting, as well as given tips in managing social media accounts both instagram and facebook to be interesting and can be maximized for digital promotional media so as to contribute in facing the global market era and able to participate in developing creative industries.
\end{abstract}

Keywords: digital marketing; nasyiatul 'aisyiyah; webinar; comunity service. 


\section{PENDAHULUAN}

Seluruh dunia sekarang ini telah terhubung secara daring, digitalisasi merajai semua sendi kehidupan. Batasan waktu dan jarak bukan menjadi halangan untuk melakukan aktivitas apapun secara langsung, termasuk dalam melakukan aktivitas bisnis dan perdagangan. Mengiringi laju perkembangan teknologi, proses bisnis baik penjualan maupun pemasaran juga mengalami perubahan, dari traditional marketing menjadi digital marketing. Traditional marketing atau proses penjualan dan pemasaran secara tradisional perlahan mulai tergeser karena digital marketing menawarkan kemudahan dan efektivitas yang lebih baik. Digital marketing adalah proses bisnis yang menggunakan teknologi digital sebagai sarana utama dan pendukungnya (Atshaya and Rungta 2016). Digital marketing merubah proses bisnis secara signifikan dan memudahkan pengelola bisnis dalam memasarkan produk atau jasa, meningkatkan penjualan, serta mempererat hubungan antara produsen dan konsumen.

Dengan konektivitas yang semakin meluas dan pertumbuhan laju pengguna internet dan media sosial, pemanfaatan digital marketing pun semakin meningkat. Salah satu contoh pemanfaatan digital marketing yaitu untuk memasarkan hasil industri rumahan berupa kerajinan tangan yang diciptakan oleh para ibu rumah tangga dengan tujuan memberdayakan perempuan dan menambah penghasilan keluarga (Pradiani 2018). Proses penjualan dan pemasaran yaitu dengan menggunakan pesan singkat, pesan WhatsApp, serta melalui Facebook dan Instagram. Kemudian, digital marketing juga diimplementasikan untuk membangun dan meningkatkan brand awareness oleh KIRBI (Koperasi Industri Rajutan Binong Jati) di Bandung (Oktaviani and Rustandi 2018). Digital marketing digunakan karena dianggap efektif dan efisien dalam memudahkan promosi, pengenalan produk kepada khalayak yang lebih luas sehingga branding produk bisa terbangun.

Pengguna internet dan media sosial di Indonesia semakin meningkat dari tahun ke tahun, sehingga potensi pemasaran dan penjualan secara daring sangat besar. Akan tetapi, pemasaran secara daring atau digital marketing juga harus dilakukan dengan strategi dan cara yang benar untuk memaksimalkan hasil yang dicapai (Mandal 2017). Karena digital marketing tidak hanya tentang bagaimana memasarkan produk dan jasa, tetapi telah berevolusi menjadi kegiatan memanfaatkan kanal digital sebagai aktivitas bisnis, institusi, dan proses dengan menggunakan teknologi digital (Kim, Kang, and
Lee 2019). Oleh karena itu, demi mempelajari seluk beluk digital marketing, diperlukan pelatihan yang intensif dan menyeluruh sehingga strategi tersebut dapat dimanfaatkan dengan maksimal.

Salah satu subset dari digital marketing adalah internet marketing, dimana mayoritas konten ataupun kegiatan diakses melalui internet (Minculete and Olar 2018). Selain itu, perlu dipahami juga mengenai struktur digital marketing dalam area internet marketing, yaitu:
1. Website
2. Search Engine Marketing
3. Social Media Marketing
4. Content Marketing
5. Email Marketing
6. Mobile Marketing
7. Banner Advertising

Ranah internet marketing tersebut dapat menjadi strategi yang diimplementasikan ke dalam digital marketing, sesuai dengan analisis dan pangsa pasar yang potensial.

Nasyiatul 'Aisyiyah cabang Rabak Purbalingga adalah organisasi di bawah kepengurusan Muhammadiyah yang anggotanya terdiri dari para ibu dan remaja putri. Dengan tagline "Perempuan Muda Berkemajuan" serta Visi yaitu "Terbentuknya putri Islam yang berarti bagi keluarga, bangsa, dan agama menuju terwujudnya masyarakat Islam yang sebenar-benarnya", Nasyiatul 'Aisyiyah aktif dalam memberdayakan perempuan di berbagai kegiatan, serta terus berupaya meningkatkan pengetahuan para anggotanya dengan berbagai pelatihan, salah satunya adalah dengan pelatihan digital marketing. Pelatihan digital marketing dibutuhkan untuk menghadapi era pasar global dan perkembangan industri kreatif, sehingga anggota Nasyiatul 'Aisyiyah memiliki bekal yang tepat untuk menyediakan informasi, pelayanan, dan dukungan dalam berbisnis secara digital.

Pelatihan ini menawarkan strategi digital marketing yang sesuai dalam menjawab tantangan kemajuan teknologi, menggunakan media sosial Facebook, Instagram, dan WhatsApp. Pemasaran digital menggunakan ketiga media sosial tersebut juga dilakukan untuk memasarkan produk Dino Dunots (Kusuma and Sugandi 2019), promosi oleh warga Kecamatan Medan Satria Bekasi (Andamisari 2021), serta strategi pemasaran di Facebook untuk meningkatkan minat beli (Simatupang, Efendi, and Putri 2021). Anggota Nasyiatul 'Aisyiyah cabang Rabak Purbalingga adalah perempuan-perempuan berdaya guna dan memiliki semangat belajar yang kuat, mempelajari strategi pemasaran secara digital menjadi suatu nilai tambah yang positif, apalagi di masa pandemi yang mengharuskan 
masyarakat untuk membatasi kegiatan di luar rumah sehingga potensi untuk meningkatkan pemasaran secara digital sangat menjanjikan.

\section{METODE}

Pengabdian kepada masyarakat yang bertemakan pelatihan digital marketing ini dilaksanakan pada 2 Juli 2021 secara daring karena kondisi pandemi yang belum memungkinkan untuk berkumpul secara langsung. Mitra yang menjadi sasaran pelatihan adalah anggota Nasyiatul 'Aisyiyah cabang Rabak Kabupaten Purbalingga. Nasyiatul 'Aisyiyah adalah organisasi Muhammadiyah yang anggotanya para ibu dan perempuanperempuan yang produktif serta berdaya guna dengan visi membentuk putri Islam yang berarti bagi keluarga, bangsa, dan agama menuju terwujudnya masyarakat Islam yang sebenarbenarnya. Pelaksanaan acara webinar berlangsung di kampus Universitas Amikom Purwokerto. Peserta dari anggota Nasyiatul 'Aisyiyah yang bergabung berjumlah 10 orang. Metode pelaksanaan pengabdian kepada masyarakat ini adalah metode webinar yaitu pemateri menyampaikan materi dengan media teleconference, yaitu Google Meet, mengenai konsep dan strategi digital marketing sebagai upaya untuk meningkatkan pengetahuan mengenai penjualan dan pemasaran secara daring. Interaksi dengan para anggota Nasyiatul 'Aisyiyah yang menjadi peserta diharapkan dapat maksimal agar hasil yang diharapkan pada pelatihan ini berhasil dengan baik, meskipun kegiatan tidak dilaksanakan secara tatap muka langsung. Kegiatan yang dilakukan pada pengabdian ini antara lain:

1. Observasi mitra

Sebelum menentukan ide pelatihan, terlebih dalulu mengidentifikasi kebutuhan mitra. Mitra yaitu Nasyiatul 'Aisyiyah membutuhkan informasi dan pelatihan mengenai pemasaran digital untuk mengasah keterampilan dalam menjawab tantangan terutama di masa pandemi.

2. Studi literatur

Studi literatur dilakukan untuk mendata dan mempelajari metode-metode digital marketing yang sesuai dengan keadaan masa kini dan masa pandemi.

3. Kegiatan pelatihan

Kegiatan pelatihan dilakukan secara daring karena kondisi yang belum memungkinkan untuk mengumpulkan masa secara langsung sekaligus.

4. Evaluasi

Evaluasi yang dilakukan yaitu melakukan follow-up setelah acara pelatihan selesai.
Keberlanjutan dari kegiatan pengabdian ini adalah dengan melakukan follow-up kepada peserta yaitu anggota Nasyiatul 'Aisyiyah, untuk mengetahui apakah peserta sudah mempraktikkan strategi digital marketing yang telah dipelajari pada saat pelatihan.

\section{HASIL DAN PEMBAHASAN}

Webinar pengabdian kepada masyarakat yang bertemakan pelatihan tentang digital marketing dilaksanakan pada Jumat 2 Juli 2021 , dengan memanfaatkan teknologi teleconference Google Meet. Acara ini diikuti oleh para ibu anggota Nasyiatul 'Aisyiyah Cabang Rabak Kabupaten Purbalingga. Berdasarkan observasi yang dilakukan, Nasyiatul 'Aisyiyah membutuhkan pelatihan digital marketing untuk mengembangkan keterampilan dalam pemasaran digital. Pada masa pandemi, pengetahuan tentang digitalisasi sangat penting, salah satunya yang dimanfaatkan untuk memasarkan produk/jasa di beberapa platform. Tangkapan layar pelaksanaan kegiatan dapat dilihat pada Gambar 1.

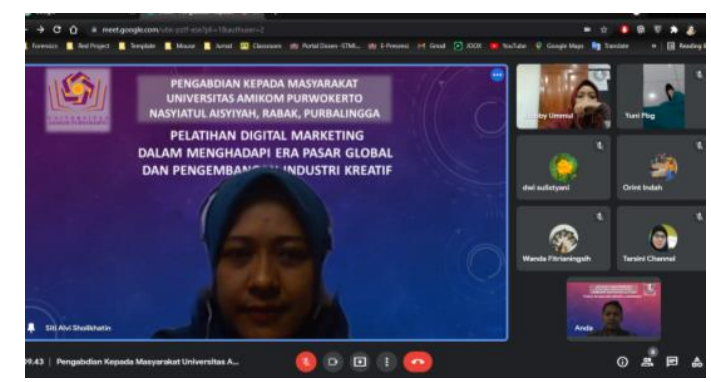

Gambar 1. Webinar digital marketing

Sesi penyajian materi disampaikan selama berkisar 30 menit, berisi tentang definisi digital marketing dan perbedaan mendasar antara pemasaran digital dengan pemasaran konvensional. Digital marketing adalah kegiatan pemasaran dengan menggunakan internet dan teknologi informasi untuk memperluas dan meningkatkan fungsi pemasaran konvensional (Taqiyya and Riyanto 2020). Pemasaran konvensional antara lain menggunakan media cetak, radio, televisi, pengeras suara atau media lain yang sifatnya tidak tergantung jaringan internet. Di sinilah keefektifan digital marketing atau pemasaran digital berperan, yaitu mampu menjangkau lebih banyak pelanggan yang potensial karena konektivitasnya lebih luas.

Mengapa penting untuk mengenal pemasaran digital terutama di masa pandemic seperti sekarang ini? Beberapa alasannya antara lain: konsumen cenderung mencari informasi di internet sebelum memutuskan membeli produk, digital marketing lebih hemat biaya, digital 
marketing dapat membantu bisnis untuk mengikuti tren, digital marketing dapat membangun kepercayaan publik terhadap brand atau produk. Selain itu, aktivitas pemasaran menjadi lebih interaktif dan terpadu serta meudahkan interaksi antara produsen, pasar dan calon konsumen. Pemasaran digital memudahkan pebisnis memantau kebutuhan dan keinginan calon konsumen, sementara calon konsumen pun dimudahkan dalam mencari dan mendapatkan informasi produk yang diinginkan (Woelandari and Setyawati 2019).

Memulai pemasaran digital tidaklah sulit. Yang perlu dilakukan pertama yaitu menyiapkan alat dan produk yang hendak dipasarkan, kemudian siapkan konten, dapat berupa foto, video, atau tulisan yang menarik, terakhir lakukan unggah konten kemudian evaluasi unggahan tersebut dari feedback yang masuk. Pembahasan selanjutnya adalah strategi pemasaran digital menggunakan WhatsApp. WhatsApp memiliki fitur story yang dapat dimanfaatkan untuk memasarkan produk atau jasa sehingga dapat menjangkau calon konsumen. Tahapan pemasaran digital menggunakan WhatsApp antara lain:

1. Mengumpulkan kontak pelanggan

2. Meminta calon pelanggan menyimpan nomor anda

3. Buat persona yang menarik

4. Tawarkan konten yang relevan kepada pelanggan

5. Berinteraksi melalui grup

6. Membalas pesan dengan cepat

7. Konsisten dalam mempromosikan produk

Contoh tata cara untuk melakukan pelatihan digital melalui story WhatsApp dapat dilihat pada Gambar 2.

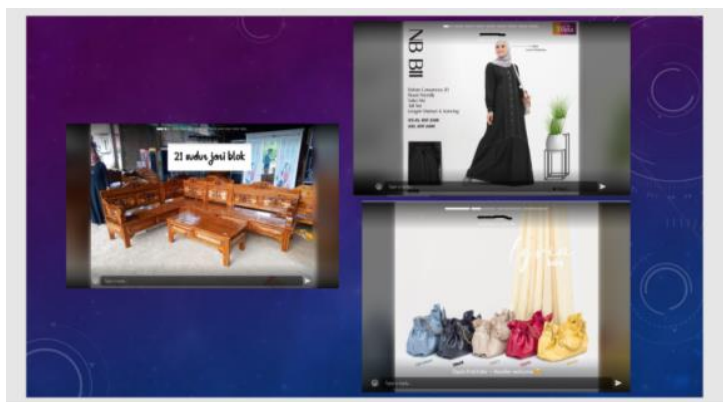

Gambar 2. Contoh WhatsApp story

Media selanjutnya untuk pemasaran digital yaitu Facebook. Facebook memiliki fitur marketplace yang berisi pelbagai kategori produk dan memudahkan calon konsumen untuk memilih barang yang diinginkan, serta memudahkan pebisnis untuk memasarkan produknya. Facebook juga menyediakan fitur group untuk mewadahi komunitas yang memiliki minat atau berbisnis di bidang yang serupa. Kedua fitur yang terdapat di Facebook tersebut dapat dimaksimalkan untuk mengembangkan bisnis, bahkan untuk pemula. Cara-cara untuk memulai memasarkan barang atau jasa di Facebook antara lain:

1. Mulai dengan tujuan yang jelas

2. Kenali target pasar

3. Ciptakan konten yang menarik

4. Jadwalkan posting konten dengan baik (Kamis, Jumat, Sabtu, dan Minggu)

5. Aktif berkomunikasi dengan audiens

6. Tentukan budget yang sesuai

Contoh tata cara untuk melakukan pelatihan digital melalui story WhatsApp dapat dilihat pada Gambar 3.

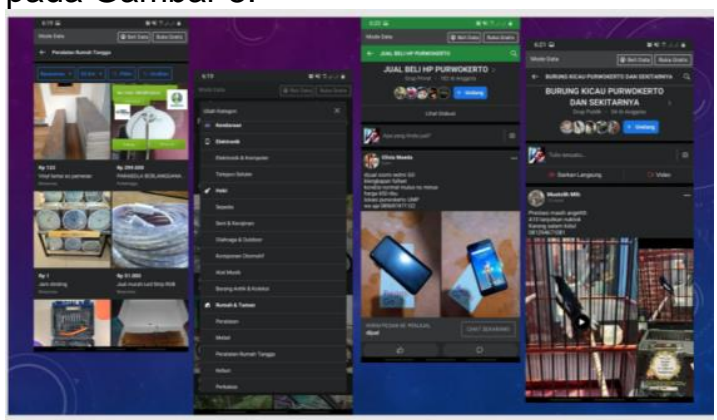

Gambar 3. Contoh marketplace di Facebook

$\begin{array}{ccc}\text { Media } & \text { terakhir yang menjadi } \\ \text { pembahasan } & \text { digital marketing adalah }\end{array}$ Instagram. Sebagai media dengan pengguna salah satu yang terbanyak di Indonesia, Instagram bisa menjadi media promosi yang sangat efektif. Dengan fitur yang mengedepankan unggahan foto di feed serta story yang mudah digunakan, Instagram memanjakan penggunanya, baik calon konsumen atau pebisnis dalam memulai pemasaran digital. Beberapa cara yang dilakukan untuk melakukan pemasaran digital di Instagram antara lain:

1. Optimalkan username dan bio

2. Gunakan profile photo menarik

3. Ikuti akun Instagram lain dalam industri yang sama

4. Perhatikan waktu unggah konten (hari Senin, Rabu, Kamis, Sabtu sore)

5. Gunakan gaya visual yang konsisten

6. Selalu gunakan caption pada unggahan

7. Manfaatkan instagram story untuk konten pendek

Contoh tata cara untuk melakukan pelatihan digital melalui story WhatsApp dapat dilihat pada Gambar 4. 


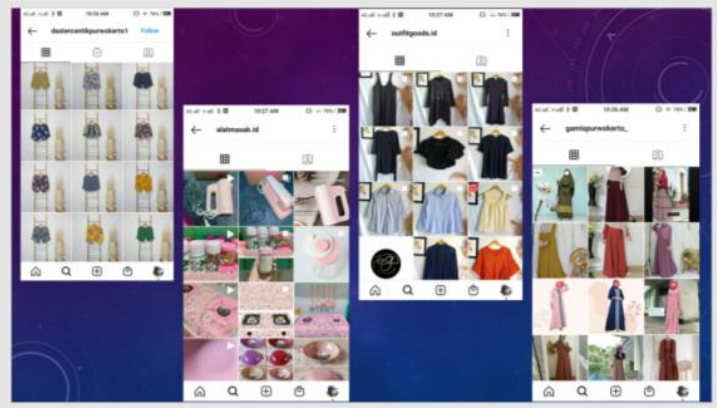

Gambar 4. Contoh pemasaran di Instagram

Pelatihan ini diakhiri dengan sesi tanya jawab serta melatih peserta untuk membuat contoh story yang menarik di WhatsApp. Halhal yang perlu diperhatikan antara lain, sudut foto yang jelas dan menampakkan seluruh elemen produk, kemudian penggunaan tulisan atau caption yang menarik dan mengandung ajakan kepada calon konsumen. Peserta dari Nasyiatul 'Aisyiyah sangat antusias dalam mempraktikkan pelatihan ini meskipun dilakukan secara daring dan mereka berniat untuk mencoba melakukan pemasaran digital melalui akun media sosial masing-masing. Keberlanjutan dari acara ini yaitu pemantauan yang dilakukan kepada anggota yang telah mengikuti acara, kendala-kendala atau kesulitan yang dihadapi dapat difalitasi melalui pesan sehingga para anggota tetap mendapatkan pendampingan yang kontinyu.

\section{SIMPULAN DAN SARAN}

Pelatihan digital marketing dilakukan terhadap anggota Nasyi'atul Aisyiyah cabang Rabak Purbalingga dengan metode webinar, yaitu memberikan informasi secara daring mengenai strategi digital marketing, dengan tujuan agar ilmu pemasaran secara digital dapat diimplementasikan secara maksimal oleh anggota Nasyi'atul Aisyiyah. Apalagi di masa pandemi dimana kegiatan transaksi melalui internet semakin marak dilakukan, maka momentum ini dirasa tepat untuk belajar mengembangkan keahlian berbisnis dan mengamalkan ilmu digital marketing demi meningkatkan pendapatan keluarga dan memberdayakan perempuan di tengah masyarakat. Media yang digunakan untuk digital marketing yang diajarkan pada webinar ini yaitu: Whatsapp, Facebook, dan Instagram, dimana ketiga media sosial tersebut merupakan salah satu yang paling banyak digunakan sekarang, sehingga jangkauan pangsa pasarnya cukup menjanjikan.

Pada sesi tanya jawab, ibu-ibu antusias dalam menanyakan, antara lain bagaimana mengatasi kejenuhan ketika melakukan promosi dan berjualan secara online, solusinya adalah dengan tetap menjaga kedisiplinan serta komitmen tujuan awal melakukan penjualan dan pemasaran online. Kunci dari keberhasilan pemasaran online adalah intensitas, kecepatan respon, serta kedisiplinan. Diakhir sesi, ibu-ibu mempraktikkan bagaimana caranya membuat story di WhatsApp agar menarik, serta diberi tips-tips dalam mengelola akun media sosial baik Instagram maupun Facebook agar menarik dan dapat dimaksimalkan untuk media promosi digital sehingga ikut berkontribusi dalam menghadapi era pasar global dan mampu turut serta dalam mengembangkan industri kreatif.

\section{UCAPAN TERIMAKASIH}

Terima kasih kepada ibu-ibu anggota

Nasyiatul 'Aisyiyah Rabak Kabupaten Purbalingga, Universitas Amikom Purwokerto, serta Lembaga Penelitian dan Pengabdian kepada Masyarakat Universitas Amikom Purwokerto.

\section{DAFTAR RUJUKAN}

Andamisari, Dessy. (2021). "Penggunaan Status Whatsapp Sebagai Digital Marketing Warga Kecamatan Medan Satria Bekasi Di Era New Normal." $5(1): 66-72$.

Atshaya, S., and Sristy Rungta. (2016). "Digital Marketing VS Internet Marketing: A Detailed Study." Digital Marketing VS Internet Marketing: A Detailed Study 3(1):29-33.

Kim, Juran, Seungmook Kang, and Ki Hoon Lee. (2019). "Evolution of Digital Marketing Communication: Bibliometric Analysis and Network Visualization from Key Articles." Journal of Business Research (September):0-1. doi: 10.1016/j.jbusres.2019.09.043.

Kusuma, Diana Fitri, and Mohamad Syahriar Sugandi. (2019). "Strategi Pemanfaatan Instagram Sebagai Media Komunikasi Pemasaran Digital Yang Dilakukan Oleh Dino Donuts." Jurnal Manajemen Komunikasi 3(1):18. doi: 10.24198/jmk.v3i1.12963.

Mandal, Pinaki. (2017). "Understanding Digital Marketing Strategy." International Journal of Scientific Research and Management 5(06):5428-31. $10.18535 / \mathrm{ijsrm} / \mathrm{v} 5 \mathrm{i} 6.11$.

Minculete, Gheorghe, and Polixenia Olar. (2018). "Approaches to the Modern Concept of Digital Marketing." International Conference KNOWLEDGEBASED ORGANIZATION 24(2):63-69. doi: 10.1515/kbo-2018-0067.

Oktaviani, Femi, and Diki Rustandi. (2018). "Implementasi Digital Marketing Dalam 
Membangun Brand Awareness." PRofesi Humas: Jurnal Ilmiah Ilmu Hubungan Masyarakat 3(1):1. doi: 10.24198/prh.v3i1.15878.

Pradiani, Theresia. (2018). "Pengaruh Sistem Pemasaran Digital Marketing Terhadap Peningkatan Volume Penjualan Hasil Industri Rumahan." Jurnal IImiah Bisnis Dan Ekonomi Asia 11(2):46-53. doi: 10.32812/jibeka.v11i2.45.

Simatupang, Sudung, Efendi Efendi, and Debi Eka Putri. (2021). "Facebook Marketplace Serta Pengaruhnya Terhadap Minat Beli." Jurnal Ekbis 22(1):28. doi: 10.30736/je.v22i1.695.

Taqiyya, Rahmah, and Sugeng Riyanto. (2020). "Strategi Pemanfaatan Media Sosial Facebook Dan WhatsApp Untuk Memperluas Jaringan Pemasaran Digital Benih Sayuran Oleh Wafipreneur Di Masa Pandemi Covid-19." Syntax Idea 2(10):810-23.

Woelandari, Dewi Sri, and Novita Wahyu Setyawati. (2019). "Digital Dengan Menggunakan Media Sosial Facebook Dan Instagram Bagi Industri Rumahan Di." Seminar Santika (September):62-67. 